\title{
Effect of a Patient Support Program for Idiopathic Pulmonary Fibrosis Patients on Medication Persistence: A Retrospective Database Analysis
}

\author{
Aimee M. Near (D) - Chakkarin Burudpakdee · Shilpa Viswanathan • \\ Shuchita Kaila
}

Received: March 29, 2021 / Accepted: April 28, 2021 / Published online: May 31, 2021

(C) The Author(s) 2021

\section{ABSTRACT}

Introduction: In 2015, Boehringer Ingelheim (BI) created a support program for patients with idiopathic pulmonary fibrosis (IPF) treated with nintedanib, to help patients obtain their prescription, learn about their disease and medication, and provide support in the management of their IPF. The purpose of this study was to measure the impact of the program on nintedanib persistence among patients with IPF newly treated with the medication.

Methods: A retrospective cohort analysis of BI Pharmaceuticals, Inc.'s Specialty Pharmacy (SP) database was conducted. Patients at least 18 years of age, newly treated with nintedanib from April 1, 2015 to January 31, 2018, and with at least one diagnosis of IPF were included in the study; earliest nintedanib prescription was the index date. Patients were classified into two mutually exclusive cohorts: enrolled in the patient support program within 60 days of

A. M. Near $(\varangle) \cdot$ C. Burudpakdee $\cdot$ S. Viswanathan

IQVIA, Durham, NC, USA

e-mail: aimee.near@iqvia.com

S. Kaila

Boehringer Ingelheim, Ridgefield, CT, USA index or not enrolled in the program at any time. The cohorts were compared in terms of patient characteristics, time to nintedanib discontinuation (a gap of more than 60 days between refills), and proportion of persistent patients at $6,12,18$, and 24 months after index. Time to discontinuation was compared between the cohorts using Kaplan-Meier analysis. A multivariable Cox proportional hazards model assessed the impact of program participation on time to discontinuation within the first 12 months.

Results: A total of 3114 enrolled and 9388 nonenrolled patients were identified. The proportion of patients persistent on nintedanib was higher among enrolled patients throughout the post-index period $(57.8 \%$ vs. $49.7 \%$ at 6 months, $34.7 \%$ vs. $28.9 \%$ at 12 months; $p<0.05)$. In adjusted analyses, being enrolled in the program was associated with a $21 \%$ decreased hazard of discontinuing nintedanib over the first-year post-index [hazard ratio $(\mathrm{HR})=0.79,95 \%$ CI 0.75-0.83, $p<0.05$ ).

Conclusion: Real-world evidence suggests a persistence benefit for patients with IPF treated with nintedanib who are enrolled in the patient support program.

Keywords: Idiopathic pulmonary fibrosis; Nintedanib; Patient support; Persistence; Realworld study 


\section{Key Summary Points}

Why carry out this study?

Idiopathic pulmonary fibrosis (IPF) is a specific form of chronic, progressive fibrosing interstitial pneumonia of unknown cause, occurring primarily in adults over the age of 50 , and limited to the lungs.

A patient-focused approach (such as patient support programs) that allows for active management of comorbidities and therapeutic side effects may positively affect treatment utilization and have significant impacts on slowing IPF disease progression, improving quality of life, and reducing the overall burden of IPF.

The aim of this retrospective database study was to measure the impact of a patient support program on treatment persistence among patients with IPF newly treated with nintedanib.

\section{What was learned from the study?}

The proportion of patients persistent on nintedanib was higher among enrolled patients throughout the post-index period (57.8\% vs. $49.7 \%$ at 6 months, $34.7 \%$ vs. $28.9 \%$ at 12 months; $p<0.05$ ).

This study highlighted a persistence benefit for patients with IPF treated with nintedanib who were enrolled in the patient support program.

\section{DIGITAL FEATURES}

This article is published with digital features, including a summary slide, to facilitate understanding of the article. To view digital features for this article go to https://doi.org/10.6084/ m9.figshare.14500980. 
are associated with better patient outcomes and lower healthcare resource utilization and costs [17]. A patient-focused approach (such as patient support programs) that allows for active management of comorbidities and therapeutic side effects may positively affect treatment utilization and have significant impacts on slowing disease progression, improving quality of life, and reducing the overall burden of IPF. Participation in patient support programs has been associated with positive effects on clinical (medication adherence and persistence), humanistic (quality of life and function), and economic (cost or utilization-related) outcomes, across a range of chronic diseases [17-20].

In February 2015, BI created a patient support program to provide personalized support and advice to patients with IPF prescribed nintedanib. The program connects enrolled patients with a personal care team available to them 24 hours a day, 7 days a week, that provides guidance related to IPF and treatment with nintedanib, including disease progression, side effects, financial assistance options, and local resources for support. The program also provides caregivers and physicians of patients enrolled in the program with resources and guidance on providing optimal care [21].

The patient support program had not been evaluated since its creation. The aim of this retrospective database study was to measure the impact of the program on treatment persistence among patients with IPF newly treated with nintedanib.

\section{METHODS}

\section{Data Source}

This study used data from Boehringer Ingelheim Pharmaceuticals, Inc.'s Specialty Pharmacy (SP) database, including data from patients with IPF from six large specialty pharmacies in the USA. The study used SP data from October 1, 2014 to July 31, 2018.

The database is composed of prescription records of patients with IPF who were prescribed nintedanib and had at least one filled prescription through any of the specialty pharmacies.
The data were collected every day of every month since the launch of nintedanib on October 1, 2014. Data are comprised of the following variables: dispensed prescription-related information [prescription name, National Drug Codes (NDC), receipt date, status (refill or new), quantity dispensed, days of supply, and dose prescribed], patient characteristics (age, sex, geographic region, and payer type), and prescriber characteristics [National Provider Identifiers (NPI) and office location]. Data on other patient comorbidities (e.g., other chronic conditions) were not available. Data contributions are subjected to a series of quality checks to ensure a standardized format and to minimize error rates. Patented and proprietary algorithms are used to create unique patient IDs that enable identification of the same patient's records from different SPs' data, hence avoiding duplication of patient records. All data are Health Insurance Portability and Accountability Act (HIPAA) compliant to protect patient privacy, and, therefore, institutional review board approval was not required for this study.

\section{Patient Selection}

The study included patients with IPF at least 18 years of age and with at least one nintedanib prescription between April 1, 2015 and January 31, 2018 (selection window); earliest nintedanib prescription fill date was the index date. Patients were classified into two mutually exclusive cohorts: patients enrolled in the support program within 60 days of index and patients not enrolled in the program at any time during the post-index period (detailed selection criteria depicted in Fig. 1). The selection window allowed for look-back to October 1, 2014 to confirm that there were no prior nintedanib prescriptions or support program enrollment in the pre-index period, and a minimum post-index period of 6 months to assess persistence to nintedanib. This window also allowed for at least 60 days since launch of the support program to ensure enough time for the program to become established. 


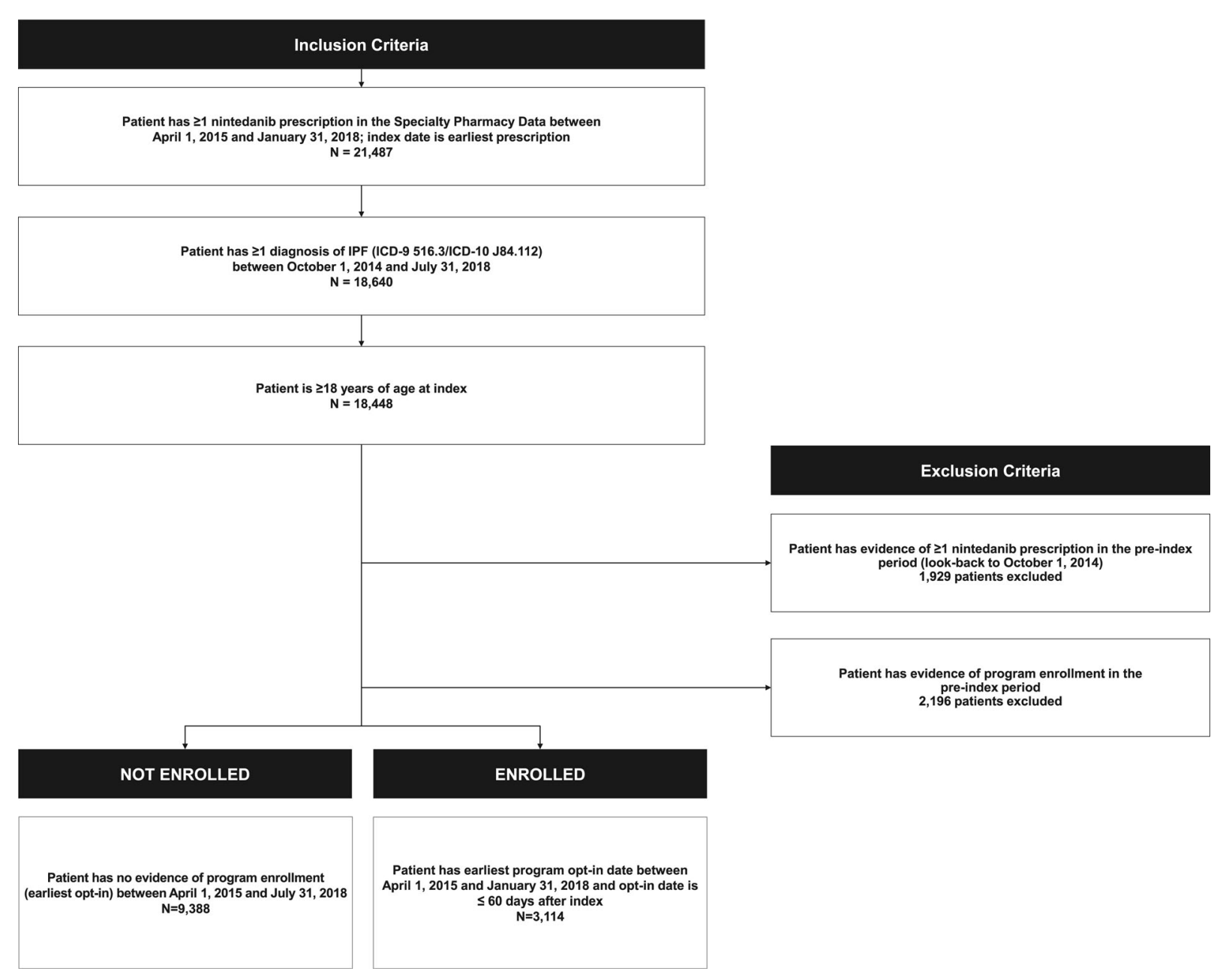

Fig. 1 Patient attrition flowchart

\section{Statistical Analysis}

Descriptive analyses include the tabular display of mean [standard deviation (SD)] values, median [interquartile range (IQR)], and ranges of continuous variables and frequency distributions for categorical variables. Missing values were considered as a separate category, where applicable.

Patient and prescriber characteristics, treatment persistence and discontinuation (defined as a gap of more than 60 days after the end of medication supply) were compared between the two cohorts. Statistical comparisons were made using chi-square tests for categorical variables and parametric $t$ test (means) and nonparametric Wilcoxon rank-sum test (medians) for continuous variables. All tests were conducted assuming a two-tailed test of significance and alpha level set a priori at 0.05 .

Time to nintedanib discontinuation was also compared between the study cohorts using Kaplan-Meier (KM) analyses, with log-rank tests used to compare survival functions. The end of the study period (July 31, 2018) was used as the end date for the KM analyses.

Upon confirmation of proportional hazards assumption, a multivariable Cox proportional hazards model was developed to assess the impact of support program participation on 
Table 1 Patient and prescriber demographic characteristics for enrolled and non-enrolled cohorts

\section{Enrolled cohort} $N=3114$

Patient characteristics

Age group $(n, \%)$

$$
<50 \text { years }
$$

$50-64$ years

65-74 years

$\geq 75$ years

Age at index (years)

Mean (SD)

Median (IQR)

Min-max

Gender $(n, \%)$

Male

Female

Index treatment year $(n, \%)$

2015

2016

2017

2018

Patient region $(n, \%)$

Northeast

Midwest

South

West

Unknown

Payer type $(n, \%)$

Self-insured/cash

Healthcare exchange

Medicaid

Medicare

Commercial/third-party

Other
$489(15.7)$

32 (1.0)

$452(14.5)$

1203 (38.6)

$1427(45.8)$

$72.5(8.3)$

74 (11)

20-85

$1926(61.8)$

$1188(38.2)$

$1060(34.0)$

859 (27.6)

$1167(37.5)$

$28(0.9)$

$680(21.8)$

1504 (48.3)

438 (14.1)

$3(0.1)$

$1(0.0)$

$4(0.1)$

$23(0.7)$

$1411(45.3)$

906 (29.1)

$0(0)$

\section{Non-enrolled cohort} $N=9388$

$224(2.4)$

$<0.0001$

1633 (17.4)

3385 (36.1)

4146 (44.2)

71.7 (9.3)

$<0.0001$

73 (13)

0.003

18-85

$5708(60.8)$

0.298

$3680(39.2)$

$2816(30.0)$

$<0.0001$

3348 (35.7)

2961 (31.5)

$263(2.8)$

1769 (18.8)

$<0.0001$

$1843(19.6)$

$4222(45.0)$

1479 (15.8)

$75(0.8)$

$10(0.1)$

$<0.0001$

$12(0.1)$

169 (1.8)

4831 (51.5)

2687 (28.6)

$4(0.0)$ 
Table 1 continued

\begin{tabular}{llll}
\hline & $\begin{array}{l}\text { Enrolled cohort } \\
\boldsymbol{N}=\mathbf{3 1 1 4}\end{array}$ & $\begin{array}{l}\text { Non-enrolled cohort } \\
\boldsymbol{N}=\mathbf{9 3 8 8}\end{array}$ & $\boldsymbol{p}$ value \\
\hline Unknown & $769(24.7)$ & $1675(17.8)$ \\
Prescriber characteristics & & \\
Prescriber specialty $(n, \%)$ & $3(0.1)$ & $9(0.1)$ & 0.366 \\
Allergy/immunology & $282(9.1)$ & $919(9.8)$ & \\
Primary care (e.g., family medicine, internal medicine, & & \\
nurse practitioner, physician assistant) & $2764(88.8)$ & $8227(87.6)$ \\
Pulmonary critical care medicine and pulmonary disease & $65(2.1)$ & $233(2.5)$ & \\
Other & & $1788(19.0)$ \\
Prescriber region $(n, \%)$ & $485(15.6)$ & $1791(19.1)$ \\
Northeast & $655(21.0)$ & $4212(44.9)$ \\
Midwest & $1520(48.8)$ & $1520(16.2)$ \\
South & $449(14.4)$ & $77(0.8)$ & \\
West & $5(0.2)$ & \\
Unknown & & \\
\hline
\end{tabular}

$S D$ standard deviation, $I Q R$ interquartile range

time to nintedanib discontinuation (months), adjusting for patient age, sex, patient region, prescriber region, payer type, starting nintedanib strength, and nintedanib index year. For this model, the first 12 months post-index was used when available to consider an event or censor the patient.

All analyses were performed using SAS version 9.4 (SAS Institute, Inc., Cary, NC).

\section{RESULTS}

A total of 12,502 patients were identified for this study: 3114 support program patients ("enrolled" patients) and 9388 patients not enrolled in the program during the data window ("nonenrolled") patients (Fig. 1). Among enrolled patients, the mean \pm SD time between index and program enrollment was $18 \pm 15$ days.
The mean age of enrolled patients was $72.5 \pm 8.3$ years, similar to the mean age of $71.7 \pm 9.3$ years in non-enrolled patients; approximately $60 \%$ of patients were male in both cohorts (Table 1). Payer type was different between the two cohorts, with fewer enrolled patients compared to non-enrolled patients on Medicaid $(0.7 \%$ vs. $1.8 \%)$ or Medicare $(45.3 \%$ vs. $51.5 \%, p<0.0001)$. More enrolled patients were indexed in 2015 (34.0\% vs. 30.0\%) and $2017(37.5 \%$ vs. $31.5 \%, p<0.0001)$. The majority of patients in both cohorts lived in the South (48.3\% enrolled vs. $45.0 \%$ non-enrolled), with slightly more enrolled patients in the Midwest $(21.8 \%$ vs. $19.6 \%)$, and fewer in the Northeast compared to non-enrolled patients (15.7\% vs. $18.8 \%, p<0.0001)$.

In terms of prescriber characteristics, prescriber specialty was similar between the cohorts $(p=0.366)$, with over $85 \%$ of 
Table 2 Treatment persistence and discontinuation during the post-index period for patients enrolled in the patient support program, compared to non-enrolled patients

\begin{tabular}{|c|c|c|c|}
\hline & $\begin{array}{l}\text { Enrolled cohort } \\
N=3114\end{array}$ & $\begin{array}{l}\text { Non-enrolled cohort } \\
N=9388\end{array}$ & $p$ value \\
\hline Dose increase $(n, \%)^{\mathrm{a}}$ & $982(60.5)$ & $2645(60.7)$ & 0.903 \\
\hline Dose decrease $(n, \%)^{\mathrm{a}}$ & $1003(61.8)$ & $2534(58.1)$ & 0.010 \\
\hline \multicolumn{4}{|c|}{ Number of nintedanib prescription refills before discontinuation ${ }^{\mathrm{b}}$} \\
\hline Mean (SD) & $10.9(9.8)$ & $9.0(9.0)$ & $<0.0001$ \\
\hline Median (IQR) & $8(12)$ & $6(11)$ & $<0.0001$ \\
\hline Min-max & $1-44$ & $1-50$ & \\
\hline \multicolumn{4}{|c|}{ Time to nintedanib discontinuation (months) ${ }^{\mathrm{b}}$} \\
\hline Mean (SD) & $10.9(10.0)$ & $9.3(9.4)$ & $<0.0001$ \\
\hline Median (IQR) & $7.9(12.7)$ & $5.9(11.7)$ & $<0.0001$ \\
\hline Min-max & $0.5-40.6$ & $0.2-40.6$ & \\
\hline \multicolumn{4}{|c|}{ Number of patients who remained on nintedanib during the post-index period $(n, \%)$} \\
\hline 6 months post-index & $1799(57.8)$ & $4667(49.7)$ & $<0.0001$ \\
\hline 12 months post-index & $1079(34.7)$ & $2715(28.9)$ & $<0.0001$ \\
\hline 18 months post-index & $586(18.8)$ & $1611(17.2)$ & 0.035 \\
\hline 24 months post-index & $406(13.0)$ & $963(10.3)$ & $<0.0001$ \\
\hline
\end{tabular}

$S D$ standard deviation, $I Q R$ interquartile range

a Dosing increase refers to a change in dose from 100 to $150 \mathrm{mg}$ and dosing decrease refers to a change in dose from 150 to $100 \mathrm{mg}$

b Discontinuation (defined as having a gap of $>60$ days) with no nintedanib prescription refills, with end date defined as the fill date plus the days' supply of last prescription; change in strength is not counted as discontinuation

prescribers specializing in pulmonary \& critical care medicine or pulmonary disease in both cohorts (Table 1). Prescriber region was very similar to patient region, with the majority of prescribers in the South $(48.8 \%$ enrolled vs. $44.9 \%$ non-enrolled), and the most common state for prescribers being Florida. A significantly higher proportion of enrolled patients started on a dose of $150 \mathrm{mg}$ twice a day (BID) of nintedanib compared to non-enrolled patients $(86.3 \%$ vs. $81.3 \%, p<0.0001)$. Remaining patients were indexed on $100 \mathrm{mg}$ BID of nintedanib. All patients in the study had strength reported for index nintedanib.

Table 2 shows nintedanib treatment patterns during the post-index period. In terms of dosing changes during the post-index period, slightly but statistically significantly more enrolled patients had a dose decrease (defined as change in dose from 150 to $100 \mathrm{mg}$ BID) compared to non-enrolled patients $(61.8 \%$ vs. $58.1 \%$, $p=0.010$ ). Mean time to nintedanib discontinuation was significantly longer in enrolled patients $(10.9 \pm 10.0$ months vs. $9.3 \pm 9.4$ months, $p<0.0001)$, as was the mean number of nintedanib prescription refills $(10.9 \pm 9.8$ for enrolled patients vs. $9.0 \pm 9.0$ for non-enrolled patients, $p<0.0001)$. Examination of the proportion of persistent patients at different time points post-index indicated that the enrolled cohort had a significantly higher proportion of persistent patients at all time points compared to the non-enrolled cohort $(57.8 \%$ vs. $49.7 \%$ at 6 months, $34.7 \%$ vs. $28.9 \%$ at 12 months, 


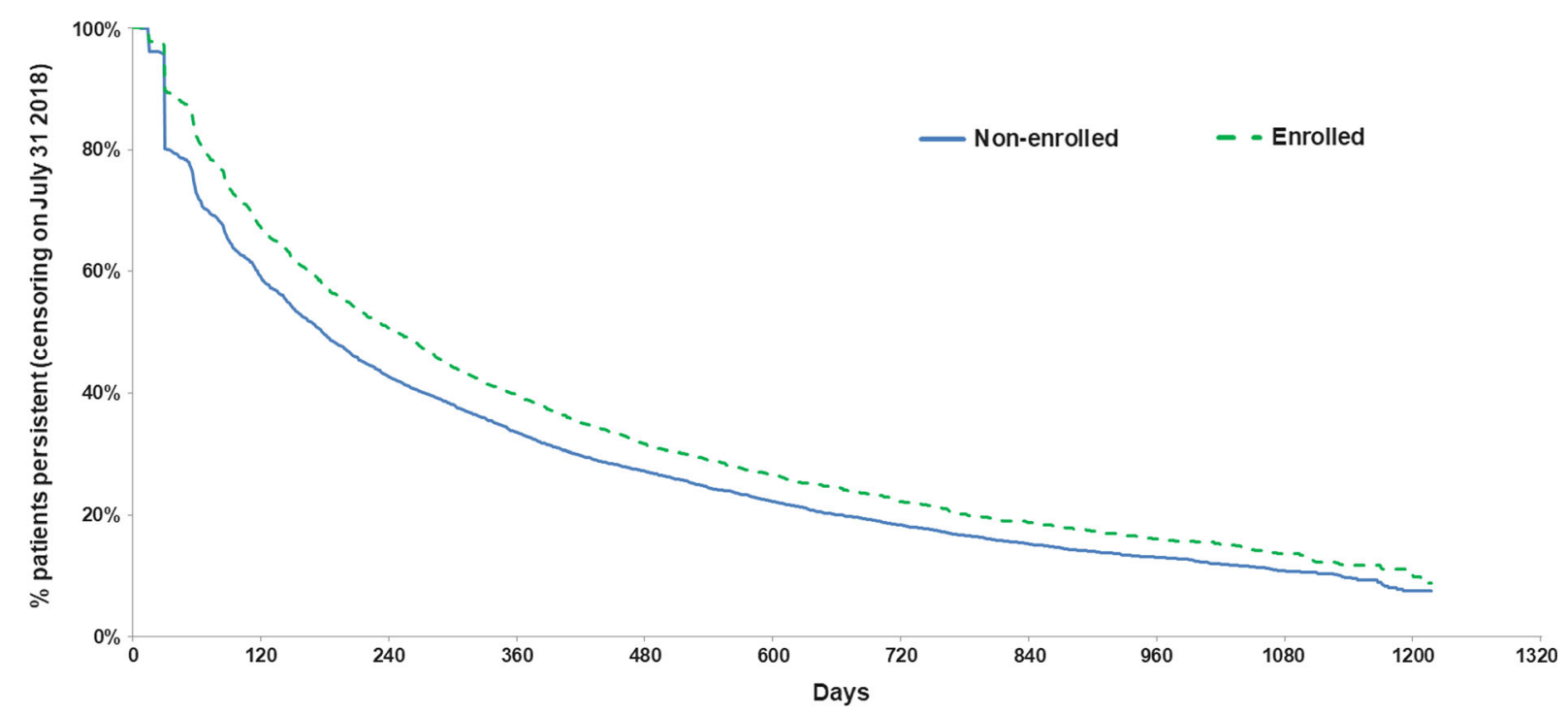

Fig. $2 \mathrm{KM}$ analysis of time from index to nintedanib discontinuation for enrolled vs. non-enrolled patients

$18.8 \%$ vs. $17.2 \%$ at 18 months, $13.0 \%$ vs. $10.3 \%$ at 24 months; all $p<0.05)$. Figure 2 depicts the time from index nintedanib to discontinuation (end of persistence) in days. Over time, the proportion of patients who remained persistent was higher among enrolled patients compared to non-enrolled patients (log-rank test $p<0.0001)$. The proportion of patients persistent to nintedanib dropped to about 50\% among enrolled patients around 9 months and the corresponding drop was observed in nonenrolled patients around 6.5 months after index. After adjustment for patient and prescriber characteristics and index nintedanib characteristics, being enrolled in the program was associated with a $21 \%$ decreased hazard of discontinuing nintedanib over the first year post-index $\quad(\mathrm{HR}=0.79, \quad 95 \%$ CI $0.75-0.83$, $p<0.05$, Table 3 ).

\section{DISCUSSION}

The results of this retrospective database study suggest a benefit in nintedanib persistence for patients with IPF enrolled in the patient support program compared to those who opted out of program participation, consistent with the realworld benefits in treatment persistence of patient support programs in other patient populations [11]. Overall, patient and prescriber demographic characteristics were similar between the two cohorts. The enrolled cohort had a slightly higher proportion of older patients compared to the non-enrolled cohort, which is consistent with the literature on improved care-seeking behaviors in older patients [22]. Further, given that, in general, older patients are less persistent to treatment compared to younger patients [23], a patient support program provides the means to overcome some of the barriers to treatment [24]. A higher proportion of non-enrolled patients were insured through Medicare (51.5\% vs. $45.3 \%$ ) despite a lower proportion of patients over 65 years of age in this cohort. This finding should be interpreted with caution considering there was a significant number of patients in each cohort with unknown payer type.

When evaluating index treatment characteristics, it was observed that a slightly higher proportion of enrolled patients initiated the higher (150 mg BID) strength of nintedanib, compared to non-enrolled patients. This could be reflective of concomitant medication treatments or comorbid disease though these data were unavailable in the study database. During the post-index period, a larger proportion of enrolled patients had a dose decrease (from 150 $\mathrm{mg}$ BID to $100 \mathrm{mg}$ BID). Further analysis is 
Table 3 Multivariable Cox proportional hazard model assessing the association between enrollment in the patient support program and time to nintedanib discontinuation

\begin{tabular}{|c|c|c|c|c|c|c|c|}
\hline & Coefficient $^{a}$ & Standard error & Chi-square & $p$ value & HR & \multicolumn{2}{|c|}{$95 \% \mathrm{CI}$} \\
\hline \multicolumn{8}{|c|}{ Enrolled in support program (ref $=$ yes $)$} \\
\hline No & 0.232 & 0.026 & 81.524 & $<0.0001$ & 1.261 & 1.199 & 1.326 \\
\hline \multicolumn{8}{|l|}{ Age at index treatment } \\
\hline Continuous & 0.011 & 0.001 & 77.304 & $<0.0001$ & 1.011 & 1.009 & 1.014 \\
\hline \multicolumn{8}{|l|}{ Gender $($ ref $=$ Female $)$} \\
\hline Male & -0.171 & 0.022 & 60.259 & $<0.0001$ & 0.843 & 0.807 & 0.880 \\
\hline \multicolumn{8}{|c|}{ Patient region $(\mathrm{ref}=$ South $)$} \\
\hline Northeast & -0.110 & 0.094 & 1.376 & 0.241 & 0.896 & 0.746 & 1.076 \\
\hline Midwest & -0.051 & 0.091 & 0.314 & 0.575 & 0.950 & 0.795 & 1.136 \\
\hline West & -0.127 & 0.114 & 1.244 & 0.265 & 0.881 & 0.705 & 1.101 \\
\hline Unknown & -0.116 & 0.280 & 0.172 & 0.679 & 0.891 & 0.515 & 1.541 \\
\hline \multicolumn{8}{|c|}{ Prescriber region (ref $=$ South $)$} \\
\hline Northeast & 0.063 & 0.093 & 0.464 & 0.496 & 1.065 & 0.888 & 1.279 \\
\hline Midwest & 0.011 & 0.092 & 0.014 & 0.905 & 1.011 & 0.844 & 1.210 \\
\hline West & 0.124 & 0.112 & 1.225 & 0.268 & 1.133 & 0.908 & 1.412 \\
\hline Unknown & 0.136 & 0.267 & 0.259 & 0.611 & 1.146 & 0.678 & 1.935 \\
\hline \multicolumn{8}{|c|}{ Payer type (ref $=$ Commercial/third-party) } \\
\hline Healthcare Exchange & -0.059 & 0.303 & 0.038 & 0.846 & 0.943 & 0.521 & 1.707 \\
\hline Medicaid & 0.074 & 0.090 & 0.674 & 0.412 & 1.077 & 0.902 & 1.285 \\
\hline Medicare & 0.025 & 0.026 & 0.949 & 0.330 & 1.025 & 0.975 & 1.078 \\
\hline Other $^{\mathrm{b}}$ & -0.007 & 0.308 & 0.000 & 0.983 & 0.994 & 0.543 & 1.816 \\
\hline Unknown & 0.322 & 0.031 & 105.941 & $<0.0001$ & 1.379 & 1.297 & 1.466 \\
\hline \multicolumn{8}{|c|}{ Index nintedanib treatment year $(\mathrm{ref}=2015)$} \\
\hline 2016 & -0.027 & 0.028 & 0.927 & 0.336 & 0.974 & 0.922 & 1.028 \\
\hline 2017 & 0.196 & 0.027 & 53.198 & $<0.0001$ & 1.216 & 1.154 & 1.282 \\
\hline 2018 & 0.773 & 0.063 & 152.103 & $<0.0001$ & 2.166 & 1.916 & 2.449 \\
\hline \multicolumn{8}{|c|}{ Nintedanib starting strength $(\mathrm{ref}=150 \mathrm{mg})$} \\
\hline $100 \mathrm{mg}$ & -0.056 & 0.030 & 3.541 & 0.060 & 0.946 & 0.893 & 1.002 \\
\hline
\end{tabular}

$H R$ hazard ratio, $C I$ confidence interval

a The model was based on first 12 months post-index to consider event or censor the patient

b Includes Self-insured/cash and Other 
needed to fully understand the reasons behind dose decrease. This could suggest a benefit of the program in persistence, with patients decreasing their nintedanib dose when necessary instead of discontinuing treatment or this could be reflective of the higher proportion of enrolled patients who started on the higher nintedanib strength.

Patients enrolled in the program had about 1.5 months longer mean time to nintedanib discontinuation compared to non-enrolled patients, and this benefit persisted in adjusted analyses. At 6 months post-index, nearly $60 \%$ of enrolled patients remained persistent, compared to only $50 \%$ of non-enrolled patients. While the absolute difference between cohorts decreased as time went on, a statistically significant benefit remained through 24 months post-index, with the enrolled cohort demonstrating approximately $30 \%$ higher relative persistence. This observed benefit in nintedanib persistence for patients with IPF enrolled in the support program is in line with previously conducted real-world studies evaluating other support programs. For example, in a systematic review by Ganguli et al., evaluating patient support programs in different populations such as type 2 diabetes mellitus, hypertension, cardiovascular disorders, asthma, and chronic obstructive pulmonary disorders, over $65 \%$ of the programs assessed reported at least one significantly positive persistence endpoint [25].

While the findings of this study suggest a benefit of the support program, limitations of the retrospective database study must be acknowledged. Adjusted analyses included only variables available in the selected database (i.e., demographic characteristics of patients and prescribers, and nintedanib prescription information) and residual confounding, possibly driven by clinical characteristics such as disease severity and medication side effects, may remain. Moreover, payer type was missing in about $20 \%$ of both cohorts, warranting further research into the importance of payer type on support program participation and impact. Available patient economic burden information, such as co-pay, had a large proportion of missing data, and hence associated results are unavailable for this study. While there were no meaningful differences in co-pay or out-ofpocket amount for the index prescription observed between the cohorts (results not shown), over half of patients did not have payment information available in the database. Furthermore, the SP database is an open database and continuous enrollment is not available; patients may be considered to have discontinued nintedanib if they switch to a pharmacy not within the SP data. To that end, the reason for patient loss to follow-up (e.g., discontinuation of nintedanib, received nintedanib in office or inpatient setting, death) is unavailable in the database. The patient's first nintedanib prescription observed in the database is assumed to be a new prescription (treatment initiation), which may not be the true treatment initiation if patients received prescriptions via other programs before they entered the database, e.g., as part of a clinical trial. Lastly, although the SP database consists of the majority of all nintedanib prescriptions (over $90 \%$ of all nintedanib prescriptions), the findings from this study may not be directly generalizable to patients filling prescriptions at pharmacies outside of the six included in the database, such as pharmacy fills through clinics and hospitals. The study is unique in using such a comprehensive data source, though it is hard to conclude whether similar results would be observed in the patients not represented in this database.

\section{CONCLUSIONS}

With over 12,000 patients in the study population, the current study was adequately powered to detect differences in patient and prescriber characteristics and nintedanib discontinuation and persistence. Future research in a database with continuous enrollment and clinical information would provide a more comprehensive picture into the benefit of the support program. However, this study suggests a persistence benefit for patients with IPF newly treated with nintedanib who are enrolled in BI's patient support program, providing rationale for encouraging wider participation. 


\section{ACKNOWLEDGEMENTS}

Funding. This study and the journal's Rapid Service Fee was funded by Boehringer Ingelheim, Ridgefield, CT, USA. All authors take complete responsibility for the integrity of the data and accuracy of the data analysis. Boehringer Ingelheim Pharmaceuticals, Inc. (BIPI) was given the opportunity to review the manuscript for medical and scientific accuracy as well as intellectual property considerations.

Authorship. All named authors meet the International Committee of Medical Journal Editors (ICMJE) criteria for authorship for this article, take responsibility for the integrity of the work as a whole, and have given their approval for this version to be published.

Authors' Contributions. Aimee M. Near: Study concept and design, statistical analysis, drafting of manuscript. Chakkarin Burudpakdee: Study concept and design, drafting of manuscript. Shilpa Viswanathan: Study concept and design, statistical analysis, drafting of manuscript. Shuchita Kaila: Study concept and design, drafting of manuscript.

Prior Presentation. This manuscript is based on work that has been previously presented at the CHEST Annual Meeting, October 2019, New Orleans, LA.

Disclosures. Shuchita Kaila was an employee of Boehringer Ingelheim at the time of the study; Aimee M. Near and Shilpa Viswanathan are employees of IQVIA; Chakkarin Burudpakdee was an employee of IQVIA at the time of the study; IQVIA was paid by BI to conduct the research study.

Compliance with Ethics Guidelines. All data are Health Insurance Portability and Accountability Act (HIPAA) compliant to protect patient privacy, and, therefore, institutional review board approval was not required for this study.

Data Availability. The datasets generated during and/or analyzed during the current study are not publicly available but are available from the corresponding author on reasonable request. The data will not be deposited.

Open Access. This article is licensed under a Creative Commons Attribution-NonCommercial 4.0 International License, which permits any non-commercial use, sharing, adaptation, distribution and reproduction in any medium or format, as long as you give appropriate credit to the original author(s) and the source, provide a link to the Creative Commons licence, and indicate if changes were made. The images or other third party material in this article are included in the article's Creative Commons licence, unless indicated otherwise in a credit line to the material. If material is not included in the article's Creative Commons licence and your intended use is not permitted by statutory regulation or exceeds the permitted use, you will need to obtain permission directly from the copyright holder. To view a copy of this licence, visit http://creativecommons.org/licenses/bync/4.0/.

\section{REFERENCES}

1. Raghu G, Collard HR, Egan JJ, et al. An official ATS/ ERS/JRS/ALAT statement: idiopathic pulmonary fibrosis: evidence-based guidelines for diagnosis and management. Am J Respir Crit Care Med. 2011;183:788-824.

2. Raghu G, Weycker D, Edelsberg J, Bradford WZ, Oster G. Incidence and prevalence of idiopathic pulmonary fibrosis. Am J Respir Crit Care Med. 2006;174(7):810-6.

3. Pérez ERF, Daniels CE, Sauver JS, et al. Incidence, prevalence, and clinical course of idiopathic pulmonary fibrosis: a population-based study. Chest. 2010;137(1):129-37.

4. King TE, Tooze JA, Schwarz MI, Brown KR, Cherniak RM. Predicting survival in idiopathic pulmonary fibrosis: scoring system and survival model. Am J Respir Crit Care Med. 2001;164(7):1171-81.

5. Ley B, Collard HR, King TE. Clinical course and prediction of survival in idiopathic pulmonary fibrosis. Am J Respir Crit Care Med. 2011;183: 431-40. 
6. Collard HR, Chen S-Y, Yeh W-S, et al. Health care utilization and costs of idiopathic pulmonary fibrosis in U.S. medicare beneficiaries aged 65 years and older. Ann Am Thorac Soc. 2015;12(7):981-7.

7. Richeldi L, du Bois RM, Raghu G, et al. Efficacy and safety of nintedanib in idiopathic pulmonary fibrosis. N Engl J Med. 2014;370(22):2071-82.

8. FDA fast-tracks 2 new medications to treat pulmonary fibrosis. The Lung Institute. 2019. https:// lunginstitute.com/blog/fda-fast-tracks-2-newmedications-to-treat-pulmonary-fibrosis/ Published 10 July 2015. Accessed 23 Nov 2019.

9. King TE Jr, Bradford WZ, Castro-Bernardini S, et al. A phase 3 trial of pirfenidone in patients with idiopathic pulmonary fibrosis. $\mathrm{N}$ Engl J Med. 2014;370(22):2083-92.

10. Lederer DJ, Martinez FJ. Idiopathic pulmonary fibrosis. N Engl J Med. 2018;378(19):1811-23.

11. Rogliani P, Calzetta L, Cavalli F, et al. Pirfenidone, nintedanib and $\mathrm{N}$-acetylcysteine for the treatment of idiopathic pulmonary fibrosis: a systematic review and meta-analysis. Pulm Pharmacol Ther. 2016;40:95-103.

12. Nathan SD, Albera C, Bradford WZ, et al. Effect of pirfenidone on mortality: pooled analyses and meta-analyses of clinical trials in idiopathic pulmonary fibrosis. Lancet Resp Med. 2017;5(1):33-41.

13. Raghu G, Rochwerg B, Zhang Y, et al. An official ATS/ERS/JRS/ALAT clinical practice guidelines: treatment of idiopathic pulmonary fibrosis. An update of the 2011 clinical practice guideline. Am J Respir Crit Care Med. 2015;192(2):e3-19.

14. Lalla D, Bengston L, Raimundo K, et al. Pirfenidone and nintedanib compliance and persistence in a real world setting. Poster presented at the American Thoracic Society Conference. 2017;195:A5351.

15. Raimundo K, Kong A, Gray S, Benloucif S, Limb SL. Adherence and persistence to antifibrotic treatments for idiopathic pulmonary fibrosis. Chest. 2017;152(4):72-8.

16. Corral M, Reddy S, Chang E, Broder M, Gokhale S, Raimundo K. Rates of adherence and persistence of antifibrotic therapies in the US Medicare population. Paper presented at the American Thoracic Society 2019 Annual Meeting; May 17-22; Dallas, Texas, 2019.

17. DiMatteo MR. Variations in patients' adherence to medical recommendations: a quantitative review of 50 years of research. Med Care. 2004;42(3):200-9.

18. Brixner D, Rubin DT, Mease P, et al. Patient support program increased medication adherence with lower total health care costs despite increased drug spending. J Manag Care Spec Pharm. 2019;25: 770-9.

19. Rubin DT, Mittal M, Davis M, Johnson S, Chao J, Skup M. Impact of a patient support program on patient adherence to adalimumab and direct medical costs in Crohn's disease, ulcerative colitis, rheumatoid arthritis, psoriasis, psoriatic arthritis, and ankylosing spondylitis. J Manag Care Spec Pharm. 2017;23(8):859-67.

20. Burudpakdee C, Khan ZM, Gala S, Nanavaty M, Kaura S. Impact of patient programs on adherence and persistence in inflammatory and immunologic diseases: a meta-analysis. Patient Prefer Adherence. 2015;9:435-48.

21. Open Doors Patient Support Program. 2019. https://www.nintedanib.com/support/open-doors Accessed Oct 2019.

22. Duck A, Pigram L, Errhalt P, Ahmed D, Chaudhari N. IPF care: a support program for patients with idiopathic pulmonary fibrosis treated with pirfenidone in Europe. Adv Ther. 2015;32(2):87-107.

23. Bausell BR. Health-seeking behavior among the elderly. Gerontologist. 1986;26(5):556-9.

24. Yeaw J, Benner JS, Walt JG, Sian S, Smith DB. Comparing adherence and persistence across 6 chronic medication classes. J Manag Care Pharm. 2009;15(9):728-40.

25. Ganguli A, Clewell J, Shillington AC. The impact of patient support programs on adherence, clinical, humanistic, and economic patient outcomes: a targeted systematic review. Patient Prefer Adherence. $2016 ; 10: 711-25$. 